\title{
COLABORAÇÃO PREMIADA COMO MÉTODOS DE OBTENÇÃO DE PROVAS E CRIME ORGANIZADO
}

\author{
AWARDED COLLABORATION AS METHODS OF OBTAINING EVIDENCE AND \\ ORGANIZED CRIME
}

\author{
Turíbio Marques Gonçalves Júnior ${ }^{1}$ \\ Bernardo Ricciardi dos Santos Brum ${ }^{2}$ \\ João Pedro Andrades Salles Soares ${ }^{3}$ \\ Pedro Antônio Lorentz Martins ${ }^{4}$
}

\begin{abstract}
RESUMO: O presente trabalho explana sobre a obtenção de provas sob colaboração premiada, instituto que ganha força com a notoriedade da criminalidade organizada, consistente na confissão do acusado ou suspeito e posterior delação de companheiro na empreitada delitiva, em troca de benefícios. Constata-se que a utilização do instituto no atual contexto brasileiro é objeto de intenso debate, continuamente citado no noticiário nacional devido a sua aplicação na Operação Lava Jato. Dividido em três capítulos, o trabalho descreve, primeiramente, o fenômeno do crime organizado, abordando os seus contornos e novas modalidades diferenciadas de investigação e meios de obtenção de provas. Assim, este trabalho emprega o método de abordagem dedutivo, aliado ao método de procedimento científico, e técnica de pesquisa bibliográfica.
\end{abstract}

Palavras-chave: Crime Organizado. Procedimento. Meios de obtenção de provas.

ABSTRACT: The present work explains about the taking of evidence under an award-winning collaboration, an institute that gains strength with the notoriety of organized crime, consisting of the confession of the accused or suspect and later plea of a partner in the criminal enterprise, in exchange for benefits. It appears that the use of the institute in the current Brazilian context is the subject of intense debate, continually mentioned in the national news due to its application in Operation Lava Jato. Divided into three chapters, the paper first describes the phenomenon of organized crime, addressing its contours and new different types of investigation and means of

\footnotetext{
${ }^{1}$ Graduado em Relações Internacionais pela Universidade de Santa Cruz do Sul (UNISC). Pós-graduado em Gestão de Segurança Pública pela UniBF. Policial Penal da SEAPEN/RS. E-mail: turibiomg@gmail.com.

${ }^{2}$ Graduado em Educação Física pela Universidade da Região da Campanha de Alegrete (URCAMP). PósGraduado em Gestão de Segurança pública pela UniBF. Policial Penal da SEAPEN/RS.

${ }_{3}^{3}$ Graduado em Direito pela Faculdade de Direito de Santa Maria (FADISMA). Pós-graduado em Gestão Penitenciária pela Faveni. Pós-graduando em Gestão em Segurança Pública pela Intervale. Pós-graduando em Direito Ambiental pela Intervale. Pós-graduando em Direito Ambiental e Econômico pela Intervale. Pósgraduando em Direito Agrário e Ambiental pela Verbo Jurídico. Policial Penal da SEAPEN/RS.

${ }^{4}$ Graduado em Direito pela Faculdade de Direito de Santa Maria (FADISMA). Pós-Graduado em Inteligência Policial pela Faveni. Policial Penal da SEAPEN/RS.
} 
obtaining evidence. Thus, this work employs the deductive approach method, combined with the scientific procedure method, and bibliographic research technique.

Keywords: Organized crime. Procedure. Means of obtaining evidence.

\section{INTRODUÇÃO}

Um dos mais graves e importantes problemas que se apresentam aos estudiosos das ciências penais é a macrocriminalidade, em especial o crime organizado, e o maior desafio contemporâneo é a descoberta de meios mais eficazes para reprimi-lo, tendo em vista que essa espécie de criminalidade se caracteriza pelo elevado grau de ofensividade à segurança pública e complexidade estrutural.

Assim, em razão da forma de atuação da criminalidade organizada, que se dá de maneira extremamente hierarquizada, com divisão de tarefas e respeito à ordem hierárquica, a matéria exigiu maior atenção do legislador, o qual realizou diversas alterações legislativas no que diz respeito à persecução penal, meios de obtenção de prova e valoração das provas nos crimes praticados por organizações criminosas, a fim de que o Estado pudesse dar uma resposta à sociedade, alcançando resultados eficazes que permitissem a desarticulação de grupos criminosos, visto que apenas a utilização dos meios tradicionais de obtenção de prova não eram mais exitosos a ponto de produzir provas capazes de atingir e desarticular uma organização criminosa.

A partir disso, com o objetivo de aperfeiçoar a persecução penal envolvendo infrações penais cometidas pela criminalidade organizada, foi criada a Lei n. ${ }^{\mathrm{O}}$ 12.850/2013, a qual trouxe diversos métodos especiais de obtenção de prova no que diz respeito às organizações criminosas, posto que a complexidade dessas organizações exigiu a modificação dos métodos tradicionais de obtenção de provas e investigação criminal.

Com efeito, o tema abordado é envolvido de relevante interesse social e jurídico, pois as infrações penais cometidas pelas organizações criminosas atingem diretamente a sociedade, gerando violência e insegurança, e fazem-se presentes em expressivas quantidades de persecuções penais no Poder Judiciário brasileiro e ainda mais aquelas de repercussão geral, como são os casos nos quais restam escancarada a vexatória corrupção política, institucionalizada nos setores públicos brasileiros.

Voltando-se à temática desenvolvida, a delação premiada é um dos temas do direito penal e processual penal que tem recebido mais destaque atualmente, sendo alvo de discussões doutrinárias, jurisprudências e até mesmo midiáticas, abarcando o senso comum. Essa predileção pelo instituto se deve, sobretudo, à denominada Operação Lava Jato, a qual, recorrentemente, dele faz uso. 
Com efeito, o enfoque do presente trabalho é a demonstração da aplicabilidade da colaboração premiada na obtenção de provas em face das organizações criminosas, visando a uma visão sistêmica e prática, da efetividade e eficácia objetivada por tal ferramenta.

A partir do estudo do instituto da colaboração premiada, haverá contribuição para a compreensão da sua aplicabilidade e legalidade, de modo a viabilizar o combate ao crime organizado, sendo o objetivo maior a desestruturação das desafiantes e sempre intrigantes organizações criminosas, nos seus diversos ramos de atuações, capacitando-se as estruturas de segurança e aparato jurídico do Estado para o adequado enfrentamento dessas.

Assim, a presente pesquisa encontra-se dividida em 2 capítulos, sendo que o primeiro aborda o fenômeno do crime organizado, o seu conceito e complexidade em aspectos gerais e o segundo apresenta os meios diferenciados de investigação e obtenção de provas relativos ao crime organizado, previstos na Lei n. $^{\mathrm{o}} \mathbf{1 2} .850 / 2013$.

Para isso, este trabalho emprega o método de abordagem dedutivo, pois a construção do saber jurídico aqui pretendida dá-se pela extração discursiva do conhecimento a partir de premissas gerais aplicáveis a hipóteses concretas, ou seja, parte-se do geral para o particular.

Quanto ao método de procedimento, tem-se o monográfico, sendo a técnica de pesquisa classificada como bibliográfica, por ser aportada em fontes teóricas pertinentes à questão.

\section{Aspectos gerais do crime organizado no Brasil e no Mundo}

A associação e organização entre criminosos sempre existiu e se desenvolveu ao longo dos tempos até tomarem a estrutura na qual se encontram hoje. A associação entre pessoas que praticam delitos objetiva aumentar os seus domínios e influências, bem como para garantia de suas próprias proteções. Considerando a interação entre vários indivíduos, o grupo acaba por praticar crimes complexos, mais graves e que, consequentemente, causam maiores prejuízos à sociedade.

É cediço que a criminalidade organizada sofreu inúmeras alterações no decorrer dos séculos e varia de acordo com o tempo e o espaço em que está inserida, de maneira não linear. Esse fenômeno se manifestou em diferentes momentos históricos e com diversas denominações ao redor do mundo, destacam-se os "comandos", no Brasil; as "máfias", na Itália; os "cartéis", na Colômbia e México; a "Yakuza”, no Japão; a “Tríade”, na China.

No que se refere à organização criminosa na Itália, mundialmente conhecida de "máfia italiana", Ana Luiza Ferro esclarece que a evolução do crime organizado na Itália classifica-se em quatro fases, sendo a primeira denominada de "fenômeno pré-mafioso", a qual abarca desde o século 
XVI até os primeiros decênios do século XIX; a segunda fase é a de "uma Máfia agrária”, em que o mafioso é, acima de tudo, um empreendedor no sentido de representar uma autoridade ausente, valendo-se da estagnação da economia do latifúndio, etapa esta que somente chegou a termo com "a derrota do movimento camponês e o sangramento dos campos mediante um expressivo fluxo migratório, cedendo a agricultura a passada ao novo equilíbrio, em nível local, nacional e europeu, dos setores produtivos"; a terceira fase é a que constitui a "urbano-empresarial", com a propagação dos mafiosos do tipo empresário; a quarta fase e última elencada é a da "Máfia financeira", em face da "financeirização da economia", ou seja, ressalta-se a necessidade de acumulação de capital ilegal por meio da "opacidade do sistema financeiro".

No caso do Brasil, não diferentemente, há organizações criminosas em diversas áreas de atividade. No campo empresarial, constata-se a existência de atividades ilícitas organizadas para a realização do contrabando de armas e outras mercadorias, do tráfico de drogas, da sonegação de tributos, da exploração do trabalho escravo, do tráfico de pessoas e tantas outras.

A criminalidade organizada também se caracteriza pelo alto poder de intimação, marcadamente pelo emprego de violência e meios cruéis contra os membros da organização e outras pessoas que violarem a "lei do silêncio". Esse mecanismo permite que os seus integrantes atuem na clandestinidade, de forma que quase impossivelmente sejam descobertos. Além disso, também é utilizado na luta contra facções rivais, na disputa pelo mercado do crime.

Portanto, analisando esse contexto, tem-se que as organizações criminosas atingiram alto grau de complexidade, além de estarem a afetar a vida de toda a população, tendo em vista a quantidade de dinheiro desviado dos cofres públicos e as atividades ilícitas perpetradas.

Para fazer frente ao fenômeno da criminalidade organizada, o qual, como visto, é um fenômeno mundial, diversos tratados e convenções internacionais foram realizados entre os países, dos quais o Brasil é signatário, entre eles se pode citar a Convenção das Nações Unidas contra o Crime Organizado Transnacional, também conhecida como Convenção de Palermo, realizada em Is de dezembro de 200o, e inserida no ordenamento jurídico brasileiro por meio do Decreto n.o 5.015 , de I2 de março de 2004, sendo a principal disposição internacional sobre o combate ao crime organizado.

Tal Convenção estabeleceu alguns conceitos para que haja conformidade entre todos os países subscritores:

a) "Grupo criminoso organizado" - grupo estruturado de três ou mais pessoas, existente há algum tempo e atuando concertadamente com o propósito de cometer uma ou mais infrações graves ou enunciadas na presente Convenção, com a intenção de obter, direta ou indiretamente, um benefício econômico ou outro benefício material; 
b) "Infração grave" - ato que constitua infração punível com uma pena de privação de liberdade, cujo máximo não seja inferior a quatro anos ou com pena superior; c) "Grupo estruturado" - grupo formado de maneira não fortuita para a prática imediata de uma infração, ainda que os seus membros não tenham funções formalmente definidas, que não haja continuidade na sua composição e que não disponha de uma estrutura elaborada;

d) "bens": os ativos de qualquer tipo, corpóreos ou incorpóreos, móveis ou imóveis, tangíveis ou intangíveis, e os documentos ou instrumentos jurídicos que atestem a propriedade ou outros direitos sobre os referidos ativos;

e) "produto do crime": os bens de qualquer tipo, provenientes, direta ou indiretamente, da prática de um crime;

f) "bloqueio" ou "apreensão": a proibic,ão temporária de trans- ferir, converter, dispor ou movimentar bens, ou a custodia, ou controle temporário de bens, por decisão de um tribunal ou de outra autoridade competente;

g) "confisco": a privação com caráter definitivo de bens, por decisão de um tribunal ou outra autoridade competente;

h) "infração principal": qualquer infração de que derive um produto que possa passar a constituir objeto de uma infração definida no Artigo 6 da presente Convenção;

i) "entrega vigiada": a técnica que consiste em permitir que remessas ilícitas ou suspeitas saiam do território de um ou mais Estados, os atravessem ou neles entrem, com o conhecimento e sob o controle das suas autoridades competentes, com a finalidade de investigar infrações e identificar as pessoas envolvidas na sua prática;

j) "organização regional de integração econômica" - uma orga- nização constituída por Estados soberanos de uma região deter- minada, para a qual estes Estados tenham transferido compe- tências nas questões reguladas pela presente Convenção, e que tenha sido devidamente mandatada, em conformidade com os os seus procedimentos internos, para assinar, ratificar, aceitar ou aprovar a Convenção, ou a ela aderir; as referências aos "Estados Partes" constantes da presente Convenção são aplicáveis a estas organizaç̃óes, nos limites das suas competências.

Acerca da ausência de definição de organização criminosa, houve movimento na doutrina e jurisprudência, após a entrada em vigor do Decreto 5.015, de 12 de maio de 2004, pela aplicação da Convenção de Palermo (Convenção das Nações Unidas sobre o Crime Organizado Transnacional), a qual possuía a conceituação de "grupo criminoso organizado" em seu art. 2.. o o que supriria a lacuna legislativa apontada acima. Nesse sentido, a compreensão de Baltazar Júnior: "Para a primeira corrente, por mim adotada, nada impedia a adoção do conceito da Convenção de Palermo para preencher a ausência de tal definição no direito interno".

Após, a Lei n.. 12.694 , de 24 de julho de 2012, apresentou no seu Artigo (Art.) 2.. de organização criminosa, porém sem conferir a ela tipificação penal. Dizia o hoje revogado conceito:

Art. 2. Para os efeitos desta Lei, considera-se organização criminosa a associação, de 3 (três) ou mais pessoas, estruturalmente ordenada e caracterizada pela divisão de tarefas, ainda que informalmente, com objetivo de obter, direta ou indiretamente, vantagem de qualquer natureza, mediante a prática de crimes cuja 
pena máxima seja igual ou superior a 4 (quatro) anos ou que sejam de caráter transnacional.

Ainda, essa lei instituiu o processo e o julgamento colegiado em primeiro grau de jurisdição de crimes praticados por organizações criminosas.

Mais recentemente, a Lei n. ${ }^{\mathrm{o}}$ 12.850, de 2 de agosto de 2013 definiu o crime organizado, dispôs sobre a investigação criminal, os meios de obtenção da prova, as infrações penais correlatas e o procedimento criminal em relação a essa espécie de criminalidade. Essa lei, assim, revogou parcial e tacitamente a Lei n.o $12.694 / 2012$, pois no que tange à formação de juízos colegiados a legislação foi mantida. Veja-se que, neste trabalho, a Lei n.․ 12.850/2013 será tratada como Lei do Crime Organizado (LCO).Acerca do conceito de organização criminosa, a LCO dispõe da seguinte forma:

Art. I. -

$[\ldots .$.

$\S^{\mathrm{I}^{\mathrm{O}}}$ Considera-se organização criminosa a associação de 4 (quatro) ou mais pessoas estruturalmente ordenada e caracterizada pela divisão de tarefas, ainda que informalmente, com objetivo de obter, direta ou indiretamente, vantagem de qualquer natureza, mediante a prática de infrações penais cujas penas máximas sejam superiores a 4 (quatro) anos, ou que sejam de caráter transnacional.

Diante de tal conceituação, impera observar-se que apesar da grande importância do tema e da existência em muitos ordenamentos de uma definição normativa de organização criminosa como se tem no Brasil -, o conceito de crime organizado ainda é uma questão bastante controvertida, dada a dificuldade de se encontrar um conceito unívoco que abarque todas as peculiaridades e variedades desses fenômenos delitivos.

Ademais, esse tipo de criminalidade, está sempre evoluindo, se transformando, buscando não somente formas mais lucrativas de atuação, mas também escapar da persecução penal.

Desse modo, a organização criminosa é de uma estrutura peculiarmente complexa, enquadrando-se nas cifras douradas do Direito Penal, relativas entre a diferença da criminalidade real com a criminalidade conhecida e investigada pelo Estado. Ou seja, a organização criminosa é verdadeiro desafio para o Estado, porquanto difícil a sua descoberta e desestruturação.

Atualmente, há diferentes tipos de organizações criminosas, engenhosamente concebidas e desenvolvidas, que dificultam, conforme visto, a investigação e processamento dos envolvidos por parte do Estado. Novamente, Mendroni expõe:

Atualmente são conhecidas quatro formas básicas de Organizações criminosas: I. Tradicional (ou Clássicas) - Das quais o exemplo mais clássico são as Máfias. Trata-se de modelo clássico das Organizações criminosas, as de tipo mafiosas que revelam características próprias (analisadas com mais detalhes em capítulo a parte, 
neste livro). Embora sejam os exemplos mais triviais, os modelos mafiosos são espécies do gênero - "Tradicional".

2. Rede (Network - Rete Criminale - Netzstruktur) - Cuja principal característica é a globalização. Forma-se através de um grupo de experts sem base, vínculos, ritos, e também sem critérios mais rígidos de formação hierárquica. É Provisória, por natureza, e se aproveita das oportunidades que surgem em cada setor e em cada local. A Organização criminosa se forma em decorrência de "indicações" e "contatos" existentes no ambiente criminal, sem qualquer compromisso de vinculação (muito menos em caráter permanente), age em determinado espaço territorial favorável para a prática dos delitos propostos, durante tempo relativamente curto (no geral alguns meses) e depois se dilui, sendo que seus integrantes - cada um vai se unir a outros agentes, formando um novo grupo em outro local.

3. Empresarial Formada no âmbito de Empresas lícitas - licitamente constituídas. Neste formato, também modernamente chamadas de Organizações criminosas, os empresários se aproveitam da própria estrutura hierárquica da empresa. Mantém as suas atividades primárias lícitas, fabricando, produzindo e comercializando bens de consumo para, secundariamente, praticar crimes fiscais, crimes ambientais, cartéis, fraudes (especialmente em concorrências - licitações, dumping, lavagem de dinheiro, falsidades documentais, materiais ideológicos, estelionatos,, etc.).

4. Endógena. Trata-se de espécie de organização criminosa que age dentro do próprio Estado, em todas as suas esferas - Federal, Estaduais e Municipais, envolvendo, conforme a atividade, cada um dos Poderes, Executivo, Legislativo ou Judiciário. É formada essencialmente por políticos e agentes públicos de todos os escalões, envolvendo, portanto, necessariamente, crimes praticados por funcionários públicos contra a administração pública (corrupção, concussão, prevaricação, etc.). Mas também, quase que inevitavelmente outras infrações penais como aquelas que se relacionam direta ou indiretamente. São Exemplos conhecidos no Brasil: O caso do Mensalão, Sanguessugas, dos Correios, Satiagraha, Castelo de Areia, Caso da Máfia dos Fiscais (SP), milícias (RJ), etc. É forma de organização criminosa denominada, na doutrina alemã de Kriminalität der Mächtigen - "Criminalidade dos Poderosos”.

Quanto aos requisitos para ser considerada uma organização criminosa, os elementos

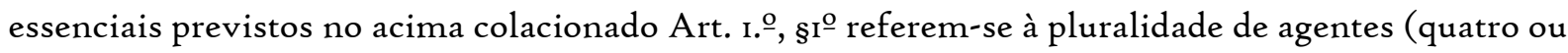
mais pessoas), a associação dessas pessoas organizadamente, a divisão de tarefas, a existência de uma finalidade, qual seja a obtenção de vantagem de qualquer natureza, além de que haja prática de infrações penais com penas máximas superiores a quatro anos ou de caráter transnacional.

Em que pese a lei traga um conceito para tipificar o crime organizado, não há um consenso no conceito de crime organizado, e a tentativa de defini-lo pormenorizadamente, através de conceitos estritos, ocasionaram tentativas frustradas, pois embora haja vários conceitos sobre as organizações criminosas nenhuma foi capaz de definir essas organizações na sua integralidade.

Desse modo, importante o estudo dos institutos específicos previstos na LCO, visto que legislador não se preocupou em fazer uma mera conceituação do que é o crime organizado, mas houve a intenção de criar mecanismos de obtenção de prova a instrumentalizando, para que a investigação 
de crimes cometidos por organizações criminosas obtenha dados concretos, para então auxiliar no desmantelamento dessas organizações, sendo este o tema do subitem a seguir.

\section{Investigação e meios de prova em face do crime organizado}

Consoante exposto no item anterior, a macro criminalidade viabilizada pelas organizações criminosas atuantes é um dos mais graves e importantes problemas de segurança pública e estruturação social. Tendo-se em vista a complexa estrutura hierarquizada na qual se amparam as organizações criminosas e o velado segredo mantido entre os integrantes da organização criminosa, torna-se evidente que a utilização dos tradicionais métodos de investigação é insuficiente para desvendá-las e/ou coibi-las.

Observação cuidadosa é trazida por Paulo Augusto Moreira Lima no sentido de demonstrar a virada necessária para a investigação da criminalidade organizada:

A análise do modus operandi destes 'velhos delitos' é suficiente a demonstrar que raramente virão à tona por confissão, prova testemunhal ou flagrante. Se os julgadores se contentarem apenas com esse tipo de prova, assistiremos a uma saraivada sem fim de absolvições, pois a experiência demonstra que nos casos pertinentes à macrocriminalidade impera forte código de silêncio na instrução criminal.

Assim, a não compreensão de que as novas formas criminosas não podem ser demonstradas pelos meios clássicos de prova resulta, no mais das vezes, na exigência de produção de prova impossível (diabólica), o que acaba por conduzir ao reconhecimento de nulidades e absolvições.

Não se pode negar que o desejo de todo o juiz criminal é poder julgar com uma relativa certeza da ocorrência do crime, o que é costumeiramente alcançado nos crimes clássicos por provas diretas como confissões, prisões em flagrante e testemunhas que presenciaram o fato. Mas, diante da nova criminalidade que se apresenta, praticada de forma dissimulada, às ocultas, por vezes mediante a utilização de 'laranjas' e empresas de fachada, o juiz que exige provas diretas como pressuposto inarredável para proferir eventual condenação, não se contentando com a prova possível, no mais das vezes indiciária, coloca a sua tranquilidade pessoal acima da responsabilidade que tem como julgador.

Nesse contexto, a LCO preconizou que, em qualquer fase da persecução penal - o que inclui a fase de investigação e processo penal -, serão permitidos diferenciados meios de obtenção de prova. Veja-se que no Art. 3. ํ da LCO há indicação da natureza jurídica de meio de obtenção de prova, e não um meio de prova propriamente dito. A respeito da diferença entre meio de prova e meio de obtenção da prova, cumpre observar a doutrina de Gustavo Badaró:

Enquanto os meios de prova são aptos a servir, diretamente, ao convencimento do juiz sobre a veracidade ou não de uma afirmação fática (p. ex., o depoimento de uma testemunha, ou o teor de uma escritura pública), os meios de obtenção de provas (p. ex.: uma busca e apreensão) são instrumento para a colheita de 
elementos ou fontes de provas, estes sim, aptos a convencer o julgador (p. ex.: um extrato bancário [documento] encontrado em uma busca e apreensão domiciliar). Ou seja, enquanto o meio de prova se presta ao convencimento direto do julgador, os meios de obtenção de provas somente indiretamente, e dependendo do resultado de sua realização, poderão servir à reconstrução da história dos fatos.

Diante dessas inovadoras formas de obtenção de prova, Masson e Marçal referem que "O que deve ser buscado pelos atores da persecução penal, isso sim, é o justo equilíbrio entre o garantismo e a efetividade da sanção, garantismo negativo e garantismo positivo, na mesma medida (...)”.

Resta evidente, assim, que na LCO o legislador não só se preocupou em trazer uma definição de organização criminosa, mas também de criar uma normalização, com a tipificação do crime e institutos correlatos, assim como definir meios para a investigação e o combate específico em detrimento do crime organizado.

Com efeito, inicia-se a breve análise dos meios de provas na LCO, observando-se, primeiramente, o Art. $3 . \stackrel{\circ}{\text { da lei: }}$

Art. 3. Em qualquer fase da persecução penal, serão permitidos, sem prejuízo de outros já previstos em lei, os seguintes meios de obtenção da prova:

I - colaboração premiada;

II - captação ambiental de sinais eletromagnéticos, ópticos ou acústicos;

III - ação controlada;

IV - acesso a registros de ligações telefônicas e telemáticas, a dados cadastrais constantes de bancos de dados públicos ou privados e a informações eleitorais ou comerciais;

$\mathrm{V}$ - interceptação de comunicações telefônicas e telemáticas, nos termos da legislação específica;

VI - afastamento dos sigilos financeiro, bancário e fiscal, nos termos da legislação específica;

VII - infiltração, por policiais, em atividade de investigação, na forma do art. II; VIII - cooperação entre instituições e órgãos federais, distritais, estaduais e municipais na busca de provas e informações de interesse da investigação ou da instrução criminal.

Acerca da ação controlada (Art. $3^{\circ}$, inciso III, da LCO), o caput do Art. 8.ํ da mesma Lei indica que:

Art. 8․ Consiste a ação controlada em retardar a intervenção policial ou administrativa relativa à ação praticada por organização criminosa ou a ela vinculada, desde que mantida sob observação e acompanhamento para que a medida legal se concretize no momento mais eficaz à formação de provas e obtenção de informações.

Segundo a doutrina de Renato Brasileiro de Lima: 


\begin{abstract}
A depender do caso concreto, é estrategicamente mais produtivo, sob o ponto de vista da colheita de provas, evitar a prisão prematura de integrantes menos graduados de determinada organização criminosa, pelo menos num primeiro momento, de modo a permitir o monitoramento de suas ações e subsequente identificação e prisão dos demais membros, notadamente daqueles que exercem o comando da societas criminis. Exsurge daí a importância da chamada ação controlada, que consiste no retardamento da intervenção do aparato estatal, que deve ocorrer num momento mais oportuno sob o ponto de vista da investigação criminal.
\end{abstract}

Para a efetivação da medida é necessária a ocorrência de dois requisitos: a existência de informações que apontem a ocorrência de outros atos ilícitos relacionados à prática investigada e que justifiquem o retardo na intervenção, além da prévia comunicação ao juiz competente.

Nesse caso, concede-se à Polícia, especialmente ao Delegado de Polícia responsável pela equipe, o direito de aguardar a oportunidade mais eficiente para atuar, de modo a obter-se a situação mais favorável para a obtenção de provas. Mesmo sendo aplicada na investigação, faz-se imprescindível a autorização judicial, para que a atuação não se revele uma "ação descontrolada", como aponta Mendroni.

Outro meio de obtenção de prova utilizado de maneira excepcional, muito polêmico no âmbito jurídico, é a infiltração de agentes policiais nas organizações criminosas (Art. 3.o, VII, LCO). Esse instituto encontra reconhecimento em diversas convenções internacionais, como, por exemplo, a Convenção das Nações Unidas contra o Crime Organizado (Convenção de Palermo) e a Convenção das Nações Unidas contra a Corrupção (Convenção de Mérida), já referidas no item anterior deste estudo.

Alguns requisitos para a utilização do agente infiltrado são importantes a serem mencionados: a LCO estabeleceu que o Delegado de Polícia irá manifestar-se antes da decisão judicial, quando o pedido de infiltração venha do Ministério Público; a autoridade judicial necessita deferir a medida, analisando o caráter excepcional e os elementos que formaram a sua convicção.

Conforme dispõe o Art. io da LCO, a infiltração de agentes de polícia em tarefas de investigação pode ser deflagrada a partir de representação do Delegado de Polícia ou de requerimento do Ministério Público. Mas há necessidade da autorização judicial para a efetivação da infiltração policial, pressuposto que, segundo Mendroni, distingue a legislação pátria da tendência evidenciada nos Estados Unidos e países europeus, nos quais a autorização é efetivada pelo Ministério Público.

Ademais, faz-se necessária a existência de indícios suficientes para a imputação do delito de que trata o Art. I. o da LCO, sem que existam outros meios de provas viáveis. Masson e Marçal 
falam que "a infiltração deve ser precedida de outros meios de prova, ainda que também invasivos, como as interceptações de comunicações telefônicas e de dados, buscas e apreensões, etc".

No último inciso do Art. $3 .^{\circ}$ da LCO, há previsão da cooperação entre instituições e órgãos federais, distritais, estaduais e municipais na busca de informações de interesse na investigação ou da instrução criminal. Por meio dessa cooperação, busca-se a organização do Estado em detrimento da estrutura complexa do crime organizado.

A respeito disso, Masson e Marçal pontuam não considerarem a cooperação entre instituições como meio probatório, sendo "uma estratégia que pode possibilitar a obtenção de provas constantes nos arquivos dos entes estatais". Acrescentam, também, que "Não se pode olvidar que a troca de informações de inteligência é medida essencial para a prevenção e a repressão à criminalidade organizada".

Após a análise de alguns dos institutos extraordinários de meios de obtenção de provas relativos à repressão do crime organizado, aufere-se que o legislador está consciente da realidade que permeia a Justiça Criminal no que se refere à macrocriminalidade. Por conseguinte, buscou-se melhor instrumentalizar as instituições criminais consideradas desarticuladas, em face da complexidade das organizações criminosas.

Desse modo, passa-se ao ponto de estudo específico do instituto da delação/colaboração premiada.

\section{Considerações finais}

A criminalidade organizada cresceu significativamente, bem como se aperfeiçoou, apresentando cada vez mais características que dificultam o trabalho dos órgãos envolvidos na persecução penal. As organizações criminosas se definem pela estrutura hierárquica, com divisão de tarefas, sendo que cada integrante possui uma função previamente determinada, caracterizando-se como uma verdadeira empresa voltada à prática de infrações penais, tornando difícil, assim, a identificação dos envolvidos.

Além disso, considerando o "profissionalismo" com que as organizações criminosas desenvolvem suas atividades, sempre visando o melhor método de modo a que não sejam descobertos, vigora no mundo da criminalidade organizada a lei do silêncio, o que faz com que as provas acerca da identidade dos autores e partícipes, e circunstâncias do crime não sejam obtidas mediante os meios tradicionais de obtenção de prova. 
Desse modo, esse estudo foi iniciado a trabalhar-se com o fenômeno do crime organizado, que devido ao fenômeno da globalização, aproximação das comunicações e facilidade de transferência de capitais, tornou-se um acontecimento global, estando presente em praticamente todos os países do globo. Para melhor compreensão, foram abordadas as organizações criminosas mais comentadas da história, quais sejam, a máfia italiana e a estrutura de corrupção norteamericana.

Assim, a Lei n. $^{\mathrm{o}}$ 12.850/2013 (LCO) trouxe ao ordenamento jurídico brasileiro procedimentos como a ação controlada, a infiltração de agentes, a captação ambiental de sinais eletromagnéticos, ópticos ou acústicos, o acesso ao registro das ligações, dados e informações dos investigados, afastamento de sigilo financeiro, fiscal, cooperação entre órgãos e instituições, além da colaboração premiada, objetivo principal de análise nesse caso. Observa-se que nem todos esses meios são inéditos da LCO, pois já eram previstos em outras legislações. Entretanto, a LCO condensou a aplicabilidade desses meios, disciplinando seus procedimentos.

Dessa forma, especial espaço de abordagem merece o instituto da delação premiada, trabalhado no segundo e terceiro capítulos, por muitos doutrinadores tratada como traição, por conferir prêmios legais ao agente envolvido na criminalidade organizada, que, sem a menor ética, ofende todos os tipos de bens jurídicos. A delação nada mais é do que a conduta positiva do investigado ou réu em colaborar com a investigação ou com o processo penal, revelando aspectos do crime dificilmente desvendados pelas práticas tradicionais de investigação e recebendo, em troca, determinados benefícios, tais como redução da pena, perdão judicial, regime penitenciário diferenciado, conforme será elaborado na sequência.

A delação premiada não é um instituto novo no ordenamento jurídico brasileiro, motivo pelo qual importante a recapitulação das legislações que trouxeram a previsão da sua aplicação, estudando-se a evolução do mecanismo até a chegada da LCO.

O acordo de colaboração premiada, portanto, visa a obtenção de provas e informações eficazes que, somadas a outros elementos de prova, sejam capazes de interferir nas atividades da organização criminosa, seja mediante a identificação dos integrantes ou até mesmo na desarticulação da organização.

Todavia, existem críticas quanto á eficácia da colaboração premiada como meio de obtenção de prova, visto que o colaborador poderia prestar informações falsas, apenas com o objetivo de ser agraciado com os prêmios legais, sem possuir interesse em, de fato, contribuir para o sucesso da investigação ou do processo criminal. 
Desse modo, é possível concluir que a colaboração premiada caracteriza-se como um importante meio de obtenção de prova no combate ao crime organizado, demonstrando a sua eficácia no momento em que permite às autoridades competentes o acesso a informações que não seriam possíveis com uma investigação criminal comum, visto que as informações são fornecidas pelos próprios integrantes da organização que visam obter benefícios e que, para tanto, comprometem-se a prestar declarações eficazes para o combate do crime organizado.

Por último, analisa-se os direitos do colaborador, conforme previsão do Art. 5.ำ da LCO, o qual consiste em um sistema de proteção à intimidade e integridade do colaborador e a sua família. Destarte, a LCO objetivou tornar a colaboração premiada mais atrativa aos colaboradores, a eles conferindo prêmios legais mais amplos do que as legislações anteriores, disciplinando o procedimento da colaboração e conferindo proteção ao colaborador e a sua família.

\section{Referências Bibliográficas}

BADARÓ, Gustavo. Quem está preso pode delatar? 23 jun. 2015. JOTA. Disponível em: 〈http://jota.uol.com.br/quem-esta-preso-pode-delatar〉. Acesso em II mar. 2020.

BALTAZAR JUNIOR, José Paulo. Crimes federais, Io ${ }^{\mathrm{a}}$ Edição. Saraiva, 2015.

BRASIL. Lei n. 12.850/2013. Lei do Crime Organizado. Disponível em: 〈http://www.planalto.gov.br/ccivil_03/_ato20II-2014/2013/lei/li285o.htm〉.

Lei n.o 12.694, de 24 de julho de 2012.

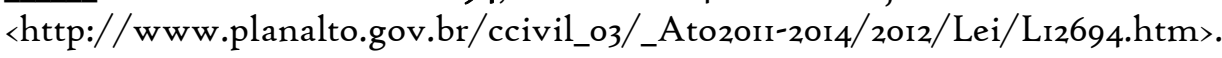

Disponível em:

Decreto n.o 5.015, de 12 de março de 2004. Disponível em: 〈http://www.planalto.gov.br/ccivil_03/_ato2004-2006/2004/decreto/d5015.htm〉.

FERRO, Ana Luiza. Crime Organizado e Organizações Criminosas Mundiais. Curitiba: Ed. Juruá, 2012.

LIMA, Paulo Augusto Moreira. A prova diabólica no processo penal. In: SALGADO, Daniel de Resende; QUEIROZ, Ronaldo Pinheiro de (Org.). A prova no enfrentamento à macrocriminalidade. Salvador: JusPodivm, 2015.

LIMA, Renato Brasileiro de. Manual de Processo Penal: volume único. 5.ed. Salvador: JusPodivm. 2017.

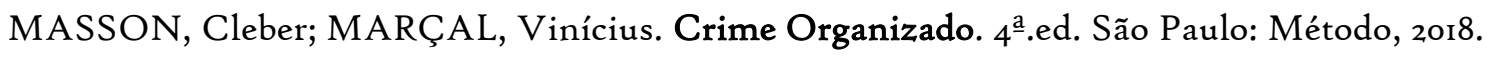

MENDRONI, Marceli Batlouni. Crime Organizado. 6ª ed. Atlas, 2016. 